A puntes del CENES

ISSN 0120-3053

Volumen 30 - №. 52

Segundo Semestre 2011

Págs. 117 - 143

\title{
Logros, retos y oportunidades para el mercado del microfinanciamiento en Colombia*
}

\section{Achievements, challenges and opportunities for the microfinance market in Colombia}

Hugo Alfonso Hernández Escolar ** Jhon Alexander M éndez Sayago ***

Nubia Stella Carreño Amaya **x*

F echa de recepción: 28 de marzo de 2011

Fecha de aprobación: 30 mayo de 2011

* Resultado del proyecto Medición e Impacto del Microcrédito, avalado por la Universidad Los Libertadores, ejecutado en el año 2010.

** Economista Universidad Nacional de Colombia y magíster en Economía de la Pontificia Universidad Javeriana, Bogotá. Docente investigador Fundación Universitaria Los Libertadores, Bogotá. Correo electrónico: hahernandeze@hotmail.com

*** Ingeniero civil y magíster en Economía Ambiental, Universidad de los Andes, Bogotá. Profesor asistente Universidad del Valle. Correo electrónico: jhon.mendez@correounivalle.edu.co

**** Economista Universidad La Gran Colombia. Maestrante en Desarrollo Empresarial Agropecuario U. Nacional de Colombia. Investigadora Fundación Universitaria Los Libertadores, Bogotá. Correo electrónico: nscarrenoa@gmail.com 


\section{Resumen}

El artículo expone los beneficios económicos derivados del espacio de financiamiento disponible para la población de menores ingresos en el país, comparando los elementos característicos de la experiencia del Grameen Bank frente a la institucionalización del microcrédito en Colombia. El problema del microfinanciamiento es examinado a la luz del análisis económico convencional. Se abordan elementos del entorno institucional en distintos países, seguidos por una reseña de la experiencia colombiana. Finalmente se explora una serie de indicador es representativos del microcrédito en nuestro medio. Los indicadores evaluados sugieren que existe espacio para la expansión del microcrédito en condiciones rentables.

Palabras clave: microcrédito, micr ofinanzas, banco de los pobres, instituciones microfinancieras, políticas del gobierno.

Clasificación JEL: D14, G21, G28.

\section{Abstract}

This article exposes economic benefits from funding space available for low income population in the country, by a comparison of characteristic elements from Grameen Bank experience in relation to microcredit institutionalization in Colombia. The problem of microfinance is examined in the light of conventional economic analysis. Institutional environment elements are treated in various countries, and then a Colombian review is presented. Finally, a series of representative indicators of microcredit are explored. The assessed indicators suggest that ther e is space for microcredit expansion with profitable condition.

Keywords: microcredit, micr ofinance, poor's bank, micr ofinance institutions, government policies.

JEL Clasification: D14, G21, G28. 


\section{Introducción}

A pesar de la abundante bibliografía disponible sobre el microcrédito, y de modo más general sobre las microfinanzas, gran parte de ella se ocupa principalmente de aspectos coyunturales, acumulados de cifras históricas o reminiscencias en torno a la inspiración que causa el modelo de los primeros "bancos de los pobres" sobre iniciativas actualmente en curso en distintas locaciones del mundo.

Para los efectos específicos de la investigación académica que brinde interpretaciones de estos fenómenos a la luz de las teorías económicas y derive en disquisiciones analíticas y recomendaciones de orden aplicado, se observa que la literatura es menos profusa, y en general suele estar ligada a un lado de la balanza: o del lado de instituciones microcrediticias para efectos ilustrativos o publicitarios, o del lado de analistas del sector financiero que ponen de manifiesto las dificultades para que el microcrédito, tal como está concebido, se inserte exitosamente dentro del universo del mercado de recursos de financiamiento (Cuéllar, 2009).

Es necesario, pues, proveer planteamientos que hagan las veces de puente entre el extremo académico y el extremo aplicado en la literatura, que distingan las distintas percepciones sobre el fenómeno del microcrédito, su dimensión frente al tipo de necesidad que pretende resolver, y las herramientas de gestión efectivas en cabeza tanto de las autoridades económicas como de organizaciones independientes.

Cabe entonces hacerse varios interrogantes sobre las potencialidades del 
microcrédito en el medio colombiano. De una parte, es pertinente saber si es favorable para los pobres la ocupación del espacio de financiamiento en términos de la brecha de tasa de interés respecto del costo del dinero en el sistema financiero formal (Yunus, 1998). De otra, es relevante conocer si en el desarrollo institucional el microcrédito sigue en líneas generales el pensamiento de Yunus o se ha desvirtuado hacia prácticas ajenas a su filosofía. Y como un tercer aspecto, es deseable evidenciar hasta qué punto la actividad microcrediticia ha generado ventajas frente a la operación financiera convencional tal como la perciben los empresarios tradicionales que recurren a la banca.

En el desarrollo del tex to se abordan estos interrogantes, para luego efectuar una recopilación de argumentos y emitir las conclusiones más relevantes sobre el estado actual del microcrédito en Colombia y su prospectiva.

\section{Una aproximación conceptual}

En muchas regiones del mundo es reconocido y aun estimado desde hace décadas el elevado tamaño de la economía informal (Schneider \& Ense, 2002). No obstante, en lo que concierne a sus mecanismos de financiación, es solo hasta la difusión de las ideas de Muhammad Yunus que la aplicación de iniciativas para dotar de crédito a segmentos de población vulnerable en términos de exclusión social, pero a la vez emprendedora, adquiere atractivo en los medios académico e institucional.

La afirmación básica de Yunus en el sentido de que los emprendedores más pobres pueden incrementar su bienestar accediendo a una financiación organizada y menos costosa que la realmente enfrentada por ellos, se convirtió en un llamado a la acción de múltiples organizaciones no gubernamentales (ONG) en un inicio, pero luego del reconocimiento de instituciones de mayor talla como las del sistema de Naciones Unidas, quedó planteado el escenario para que los sistemas financieros formales, con o sin estímulo de los gobiernos, acometieran la distinción de un segmento de clientela que incluyera a los pequeños emprendedores.

En Colombia, en el marco de la Ley Mipyme $^{2}$, la Superintendencia Bancaria (hoy Superintendencia Financiera) mediante las Circulares Externas No. 50/ 2001 y 11/2002 estableció la modalidad de microcrédito. Cada entidad vigilada por la Superfinanciera, según lo expresa este organismo, "deberá clasificar como microcrédito el conjunto de operaciones activas de crédito otorgadas a microempresas cuyo saldo de endeudamiento con la respectiva entidad no supere veinticinco (25) salarios mínimos legales mensuales vigentes" (Superfinanciera, 2002).

2 Ley 590 del 10 de julio de 2000, "Por la cual se dictan disposiciones para promover el desarrollo de las micro, pequeñas y medianas empresas". 
A su vez, "Por microempresa se entiende toda unidad de explotación económica, realizada por persona natural o jurídica, en actividades empresariales, agropecuarias, industriales, comerciales o de servicios, rural o urbana, cuya planta de personal no supere diez (10) trabajadores y sus activos totales sean inferiores a quinientos uno (501) salarios mínimos mensuales legales vigentes" (Superfinanciera, 2002). Fue así como la actividad microcrediticia recibió reconocimiento y se hizo parte constitutiva y diferenciada de las actividades de financiamiento formal.

A pesar de las anteriores definiciones, Ferrari (2004) argumenta que estas no corresponden a la población característica que debera ser objeto de la política social, esto es, personas pobres, monofactoriales, sin activos y sin calificación, y que para ellos son necesarios esquemas de intermediación no tradicional, distintos de la mecánica actual de inclusión en los conductos formales.

Precisamente, el agravamiento y la perpetuación de las condiciones de pobreza pueden percibirse mediante señales como: la diversificación de las fuentes de ingreso incursionando en labores de baja rentabilidad; la venta de activos del hogar; la disminución de la proporción del gasto en alimentos; la incorporación al mercado laboral de nuevos integrantes de la familia, a menudo los más jóvenes; y la sucesión de épocas de ahorro o desahorro, es decir sin un patrón definido (Fajury, 2009).
Ciertamente las condiciones descritas no son las deseables para un potencial usuario financiero. Tradicionalmente, las entidades financieras, con miras a la aprobación de crédito nuevo, toman como criterios más importantes el conocimiento previo del cliente y la historia crediticia (Banco de la República, 2010).

No obstante, instituciones con mucha tradición tienen a la inversión social como un valor institucional, plasmando como propósito misional el mejoramiento social, empresarial y comunitario (Financiera Compartir, 2010).

Los experimentos de réplica de la iniciativa instrumental de Yunus, el Grameen Bank, en instituciones como el Banco Solidario en Bolivia y la Fundación Contigo en Chile, han dado lugar a aseveraciones diversas sobre la adaptabilidad que pueden alcanzar los bancos de los pobres en distintos contextos culturales. Por ejemplo, se ha afirmado que el modelo de aldea y deuda comunal abordado por Yunus en Bangladesh se halla muy distante de los entornos subnormales típicos de un cinturón de miseria en una ciudad suramericana, donde la cultura del consumo invita cada vez de manera más explícita al individualismo, incluso diferenciando el tipo de bienes para cada miembro de una familia. Las brechas sociales, unidas a los conductos para hacer "dinero fácil" impiden la difusión y el atractivo del empresarismo y de la acción solidaria o mutual. No obstante, 
en contra de esa corriente algunas organizaciones, especialmente en Bolivia, han podido operar con comunidades estructuradas que han aceptado el reto de financiarse bajo el esquema de garantía solidaria.

Con base en lo anterior, cabe distinguir dos grandes líneas de acción respecto de la evolución del microcrédito. Una propugna por la plena incorporación del microempresario al sistema financiero formal, junto con todo lo que ello implica en términos de procedimiento, especialización, regulación y adopción, en general, de las reglas del mercado financiero (Otero, 2003). Esta ruta de evolución trae implícita la noción de que es el microempresario el que debe con el paso del tiempo aprehender unas reglas de juego instituidas, acoplando su esquema mental y aun rediseñando su empresa para atender tales estándares (normas de calidad, formalidades, asociación gremial, subcontratación, etc.).

La otra línea aboga por preservar razonablemente el medio en que se desenvuelve el emprendedor, buscando afinidades de actividad o de proyecto que posibiliten las sinergias o labores mancomunadas asociativas, brindando una gama de servicios complementarios de asistencia en los que la formalidad no es el objetivo per se, sino una meta a mediano plazo entre muchas otras pretendidas, como el reconocimiento de la comunidad, la eficiencia en la actividad económica desempeñada y la superación de las limitaciones, no solo en cuestión de crédito sino de proveedores, capacitación, publicidad y otras (Fardelli, 2006).

Si cada línea de pensamiento se lleva a extremos, uno de estos será el sesgo hacia el asistencialismo y el otro un sesgo hacia la perspectiva de negocio. En algunos ámbitos, las microfinanzas siguen siendo vistas como una actividad asistencialista llevada a cabo por donantes, gobiernos y entidades que "invierten en lo social" (U. Sergio Arboleda, 2006). Pero en otros, se considera que las microfinanzas exitosas se han basado en el concepto de contrato, en marcado contraste con la visión paternalista de las transferencias gratuitas o las recompensas políticas (Corporación Andina de Fomento [CAF], 2005).

Ciertamente el debate teórico se halla lejos de terminar. De una parte, Yunus afirma que las microfinanzas son para ayudar a los pobres, por lo que solo podrían ser aceptadas como negocio si revirtieran mayores beneficios a esa población. De otra, para Michael Chu, profesor de Harvard, y los banqueros de las microfinanzas en América Latina, no hay contradicción entre desarrollar un negocio para no pobres y ayudar a los pobres (Córdova, 2010).

Se hace necesario entonces pasar del esquema de solidaridad al de desarrollo, procurando una ruta intermedia que no sea ni el mercado de subsistencia ni el negocio capitalista convencional con su inclinación exclusiva al lucro. Un 
indicador de especial interés es la apertura al desarrollo comercial, porque el microempresario o emprendedor accede a mejores oportunidades en cuanto a la relación con proveedores y compradores formales (Tafur, 2008).

En parte, la presumible insatisfacción por la no profundización de esquemas de microfinanciamiento análogos a los del Grameen Bank puede ser contestada por los contextos históricos diferenciados. En Bangladesh, la iniciativa de Yunus se materializa después de la guerra de independencia que dio lugar a la emancipación política (1971). El país se hallaba desgastado, en ruina, y sus indicadores económicos y sociales eran mucho más críticos que los de nuestro contexto (Giraldo, 2009).

Esta contraposición de planteamientos ha derivado en una separación institucional bien definida. Aunque los gobiernos de los países de menor desarrollo siempre incorporan dentro de sus agendas de política el tema de la superación de la pobreza, les ha resultado particularmente cómodo alinearse con el sistema financiero formal y facilitarle a este algunas condiciones para extender su espectro de cartera al microempresariado, de modo tal que el ejercicio de gestión se limita a promover algunos cambios normativos o a ofrecer estímulos a las instituciones prestamistas. Aparte de ello, los logros de política quedan encapsulados dentro de cobertura o recursos (en su mayoría privados) desembolsados, sin un vínculo claramente definido con indicadores más precisos de superación de la pobreza.

En contraste, muchas organizaciones tradicionales mantienen su filosofía de acercamiento directo, basado en distintas formas de acompañamiento al usuario, obteniendo en muchos casos resultados loables y dignos de reconocimiento internacional.

\section{El espacio de financiamiento para los usuarios del microcrédito}

Si bien la intención primaria de los pequeños préstamos dirigidos a la población vulnerable fue la reducción de la pobreza, debe recalcarse que esta última presenta distintos matices y además se halla ligada a otras formas de exclusión social, es decir, la falta de acceso a oportunidades o la afectación en términos de derechos fundamentales. Incluso la preferencia u opción de ciertas instituciones por dirigir los préstamos a mujeres, con énfasis en madres cabezas de familia, posee implicaciones culturales, en el entendido que un empoderamiento de la mujer en el contexto familiar y social puede conllevar a transformaciones muy hondas en las estructuras económica y política de una nación.

Estas insospechadas repercusiones potenciales no parecen aún especialmente relevantes para los diseñadores de políticas públicas. Básicamente, el argumento a la luz de la teoría económica puede expresarse en los siguientes 
términos: dadas las distorsiones y fallas de mercado en la asignación de recursos, se configura una brecha en la relación de utilidades marginales entre servicios financieros y otros bienes para grupos poblacionales con nivel de ingreso diferenciado. Ello significa que una provisión de recursos líquidos hacia los estratos pobres creará una paulatina homogeneización en el ratio entre la utilidad de una unidad monetaria de crédito y una unidad monetaria de consumo de bienes. Sobre la lógica microeconómica convencional, una unidad adicional de (micro) crédito debe favorecer más a una persona pobre que a una no pobre.

Son distorsiones o fallas del mercado aquellas circunstancias del entorno económico o extraeconómico que impiden la libre concurrencia de oferentes y demandantes que propicie una situación de competencia perfecta, favoreciendo o perjudicando en especial forma a un determinado grupo de individuos. En el caso del microcrédito, por ejemplo, la institucionalización de tasas de usura impide la participación de agentes que en otras circunstancias podrían proveer de recursos a los pequeños empresarios siguiendo un conducto formal. Ello favorece el agiotismo y va en demérito de los demandantes.
Las anteriores afirmaciones de orden conceptual no están exentas de debilidades. Puede argumentarse, por ejemplo, que el acceso a recursos de financiamiento no corresponde al mercado de bienes sino al mercado de factores, ya que el microcrédito es en esencia una asignación de bienes de capital. Pero como desde la perspectiva presupuestal el interés financiero ocupa un espacio en el bolsillo del consumidor, sigue siendo razonable interpretar su adquisición en el corto plazo como un bien cualquiera por el que se paga un precio.

Sobre una perspectiva intertemporal, la predicción de beneficios para las capas de la población con menores ingresos es muy promisoria. El efecto descrito es parcial precisamente porque el capital significa la oportunidad de alcanzar mayores ingresos futuros que se traducirán en consumo, y por ende en utilidad para los pobres.

En agosto de 2009, la Misión para el Empalme de las Series de Empleo, Pobreza y Desigualdad (MESEP), a partir de información básica emitida por el DANE, hizo entrega al gobierno colombiano de las series actualizadas de mercado laboral, pobreza y desigualdad ${ }^{3}$. Se indica en el informe entregado que entre 2002 y 2008 , aunque la pobreza

$3 \quad$ La MESEP es un grupo de investigadores que elaboró una serie histórica de indicadores de mercado laboral, pobreza y desigualdad. Integrada por Jorge Iván González, Manuel Ramírez, Mauricio Santamaría, Carlos Eduardo Vélez y representantes del Gobierno Nacional, el Banco Mundial y la CEPAL. 
absoluta se redujo en 8 puntos porcentuales y la indigencia en 2 puntos porcentuales, los niveles absolutos de estas variables son de $46 \%$ en pobreza absoluta y de $17 \%$ en indigencia. En materia de concentración del ingreso, sobre el mismo período se mantuvo inalterado en 0.59 el coeficiente de Gini.

Otra muestra de la desigualdad estriba en la diferencia de resultados entre las zonas urbanas (las trece principales áreas metropolitanas ${ }^{4}$ ) y rurales. En las primeras, la reducción tanto de la pobreza como de la indigencia fue sustancial entre 2002 y 2008 (10 y 2.5 puntos porcentuales respectivamente), pero en el campo, la pobreza descendió solo 4 puntos y la indigencia se mantuvo inmodificable.

Aun durante el período de bonanza de la economía colombiana en la presente década, la informalidad no cedió, se mantuvo cerca del $55 \%$, sosteniendo así un esquema de poca generación de empleo y de inestabilidad, precariedad y sobreexplotación (Consumidores Colombia, [COCO], 2009).

Al panorama descrito cabe añadirle la escasa recurrencia al sistema financiero formal por parte de los microempresarios, con la consecuente generación de un mercado de capitales informal, con sus propias reglas y tasas. Con ello, queda planteado el reto para que todos los agentes sociales, desde el Estado hasta los microempresarios mismos, lideren iniciativas tendientes a la superación de las distorsiones de mercado y a una mejor canalización del crédito que reduzca aun más los indicadores de pobreza y desigualdad.

El resultado de la mencionada asimetría o distorsión de información hace muy vulnerable al pequeño emprendedor. El atraso a que dio lugar la crisis financiera de los noventa hizo que el grado de bancarización hacia 2005 aún estuviese por debajo de los niveles de finales del siglo XX, por ende la recuperación del sector ha sido lenta (Confederación de Cooperativas de Colombia, 2006). Si bien se interpreta que el microcrédito puede contribuir a superar la pobreza, se encuentra paradójicamente que el interés aplicado a este tipo de financiamiento es el más alto del mercado formal (Avendaño, 2006).

De hecho, dentro de la estructura de costos del microcrédito quedó estipulada una "comisión" distinta al interés y equivalente a un $7.5 \%$ del monto vigente, "a título de honorarios y comisiones" (Superfinanciera, 2007a). La existencia de la mencionada comisión procede "para los préstamos cuyo monto máximo por operación sea de 25 salarios mínimos legales vigentes y no por el saldo de

Para distintas mediciones del DANE, las áreas metropolitanas corresponden a los entornos urbanos de Bogotá,
Medellín, Cali, Barranquilla, Cartagena, Montería, Manizales, Villavicencio, Pasto, Cúcuta, Pereira, Bucaramanga e lbagué. 
endeudamiento del deudor", lo cual aumenta el espectro de recursos sobre los cuales aplica tal disposición (Superfinanciera, 2008). Las resoluciones regulatorias sobre interés bancario corriente para el microcrédito se emiten y publican conjuntamente con las relativas a las demás modalidades de financiamiento regulado (Superfinanciera, 2007b).

Como iniciativa integradora de los esfuerzos de canalización de recursos hacia las capas más pobres de la población, así como de esfuerzos en otras áreas de la bancarización, fue instituido el programa Banca de las Oportunidades, a partir de la expedición del Decreto 3078 del 8 de septiembre de 2006, con una Comisión Intersectorial encargada de coordinar y hacer seguimiento a las actividades emprendidas y con facultad para formular recomendaciones sobre el objeto del programa a las entidades públicas participantes (Minhacienda, 2006).

El citado programa apunta a integrar a todas las entidades que ofrecen servicios financieros: bancos, cooperativas, cajas de compensación, ONG, fundaciones y compañías de financiamiento comercial, para incrementar la penetración del sistema financiero entre la población de menores ingresos. El esquema consiste en la suscripción de convenios de cooperación entre las entidades y el Ministerio de Comercio, Industria y Turismo (Banco Agrario, 2007).

Parte de la filosofía del programa radica en que las Mipymes poseen mayor flexibilidad ante cambios en la demanda de sus productos, y ello ha de repercutir en beneficios elevados en un clima de recuperación económica (Mincomercio, 2003). También, como complemento a la Ley Mipyme, fue expedida la Ley 1014 de febrero de 2006 o Ley de Emprendimiento (Congreso de la República, 2006).

A pesar de la profusión y publicidad de tales acciones, persiste en algunos entornos sociales un fenómeno de autoexclusión, es decir, que los potenciales usuarios deciden no postularse para servicios microcrediticios, bien por desconocimiento de los productos y sus requerimientos, o porque consideran que no tienen las características socioeconómicas adecuadas. Tal marginamiento voluntario se concentra con especial énfasis en la población rural, la cual no posee un nivel básico de educación financiera (Banco de la República, 2009).

\section{Imprecisiones normativas}

La comprensión del fenómeno de las microfinanzas por parte del Gobierno y del sistema financiero luce hoy en día, no obstante, muy limitada. Incluso algunos analistas señalan que las acciones en pro de una regulación de las operaciones de microcrédito han sido perjudiciales, partiendo de las mismas definiciones de términos vigentes en la legislación.

Un caso de estas imprecisiones se halla 
en el Decreto 919 de 2008 (modificatorio del Decreto 519 de 2007), el cual en su artículo 1 altera la potestad de asignarle una periodicidad al interés bancario corriente, del cual se deriva a su vez la tasa de usura (Cooperativa Emprender, 2008). La modificación consiste en que: "Las tasas certificadas se expresarán en términos efectivos anuales y regirán por el período que determine la Superintendencia Financiera de Colombia, previa publicación del acto administrativo."

Esto se contrapone al artículo 326 del Estatuto Orgánico del Sistema Financiero (Superfinanciera, 1993), por el cual es la Junta Directiva del Banco de la República la instancia que tiene la atribución de recomendar la periodicidad de las tasas, lo cual reafirma la atribución del Emisor para efectuar seguimiento a los efectos de la tasa de intervención (la tasa con que se inyecta liquidez al sistema financiero) sobre el espectro de las demás tasas de interés. La modificación incorpora señales de "ruido" en el sentido de generar un espacio para la intromisión del Ejecutivo en una materia que tiene incidencia directa en el frente monetario.

Mayor connotación aun presenta el artículo 2 del mismo Decreto 919 de 2008, al sugerir una alteración a la definición de microcrédito en los siguientes términos: "Microcrédito: es el constituido por las operaciones activas de crédito a las cuales se refiere el artículo 39 de la Ley 590 de 2000, o las normas que la modifiquen, sustituyan o adicionen, así como las realizadas con microempresas en las cuales la principal fuente de pago de la obligación provenga de los ingresos derivados de su actividad".

Si bien la última parte del texto posee la ventaja de relacionar el concepto de microcrédito con los ingresos operativos de la microempresa, el artículo 39 de la Ley 590 de 2000 (Ley Mipyme) solamente define al microcrédito como "sistema de financiamiento a microempresas", y dado que el decreto no altera (y no puede alterar, por jerarquía normativa) lo mencionado en la Ley 590, surge de inmediato una confusión.

También se generó incertidumbre con el supuesto cambio en el límite a las operaciones individuales de un microcrédito, de 25 salarios mínimos mensuales legales vigentes (smmlv) a 120 , pero la intención del decreto es realmente diferenciar entre una operación individual y el saldo agregado de endeudamiento con operadores del sistema financiero. Aun así, la mención de este nuevo límite ha sido calificada como contraria al fomento de la industria microcrediticia.

El artículo 4 del Decreto 919 alude a un régimen de transición para acoplar lo dispuesto en el artículo 1, y ello forzó a conservar inmodificable durante gran parte de 2008 el interés bancario corriente aplicado a las operaciones de microcrédito, mientras que en los demás segmentos del crédito siguió siendo posible el ajuste continuo de tasas, en sintonía con el comportamiento de la 
economía. Ello se traduce en menos incentivo para las entidades especializadas en microcrédito e incluso menores utilidades. Dada la existencia del citado techo para las operaciones de microcrédito, cuando la microempresa crece la definición se queda corta, porque si bien el microempresario mantiene tal calidad, no ocurre lo mismo con sus transacciones, y se desconoce su nivel de riesgo. La cartera queda clasificada como comercial, desconociendo su origen y afectando tanto al usuario como a la entidad financiera en materia de tasa de interés, comisiones, provisiones y seguimiento (Meléndez, 2007).

Del modo expuesto, las disposiciones normativas, aun bajo su aparente intención constructiva, conducen o bien a dificultades interpretativas o a generar desmotivación en el sistema financiero para reforzar su participación en la otorgación de microcréditos.

En síntesis, aunque como tal no hay evidencia ni aparente incentivo para que los recursos fluyan hacia usuarios no pretendidos o caracterizados, sí existen barreras explícitas para los microempresarios cuyo perfil no encaja en el detalle de las disposiciones legales sobre la materia.

\section{Conformidad del esquema vigente frente a la filosofía del microcrédito}

En cuanto a la posibilidad de que la actividad microcrediticia actual no responda integralmente a la idea original de Yunus sobre la canalización de crédito hacia los pobres, debe aclararse que, en primer lugar, un programa de acción destinado a favorecer la financiación del microempresariado no tiene necesariamente que acogerse a un molde filosófico predeterminado, siempre y cuando se adecúe a la normatividad establecida y reporte beneficios tanto para los destinatarios del programa como para la misma institución microcrediticia. $Y$ en segundo término, la evolución de las ideas es perfectamente legítima, de manera que cualquier reforma efectuada a los experimentos pioneros del microcrédito debe ser bienvenida si logra los mismos o mejores cometidos en términos de coberturas, costos o calidad de los servicios ofrecidos, pudiendo decirse lo mismo con respecto a los impactos, aunque en esta esfera hay una marcada heterogeneidad en cuanto a las técnicas de evaluación utilizadas en el ámbito académico.

Esto no obstante, no debería eximir a los investigadores de abordar al menos tres características esenciales de la concepción original, como lo son la capacidad de pago de los pobres, los servicios integrados al crédito y la ausencia o redefinición de las garantías. A este propósito se dirige la presente sección.

\subsection{Implicaciones de la capacidad de pago}

Como fue expuesto en la sección precedente, el sustento para argumentar la viabilidad de una mejoría sustancial 
en el bienestar de los pobres es el diferencial de tasas de interés contratadas y pagadas respecto de los niveles vigentes en el mercado formal. Una forma alterna de representar el espacio de acción de las instituciones microfinancieras, en lo sucesivo denotadas por $\mathrm{IMF}^{5}$, y demás operadores de microcrédito, es a través de un esquema convencional de oferta $y$ demanda (Gráfico 1).

Gráfico 1. Oferta y demanda de recursos financieros

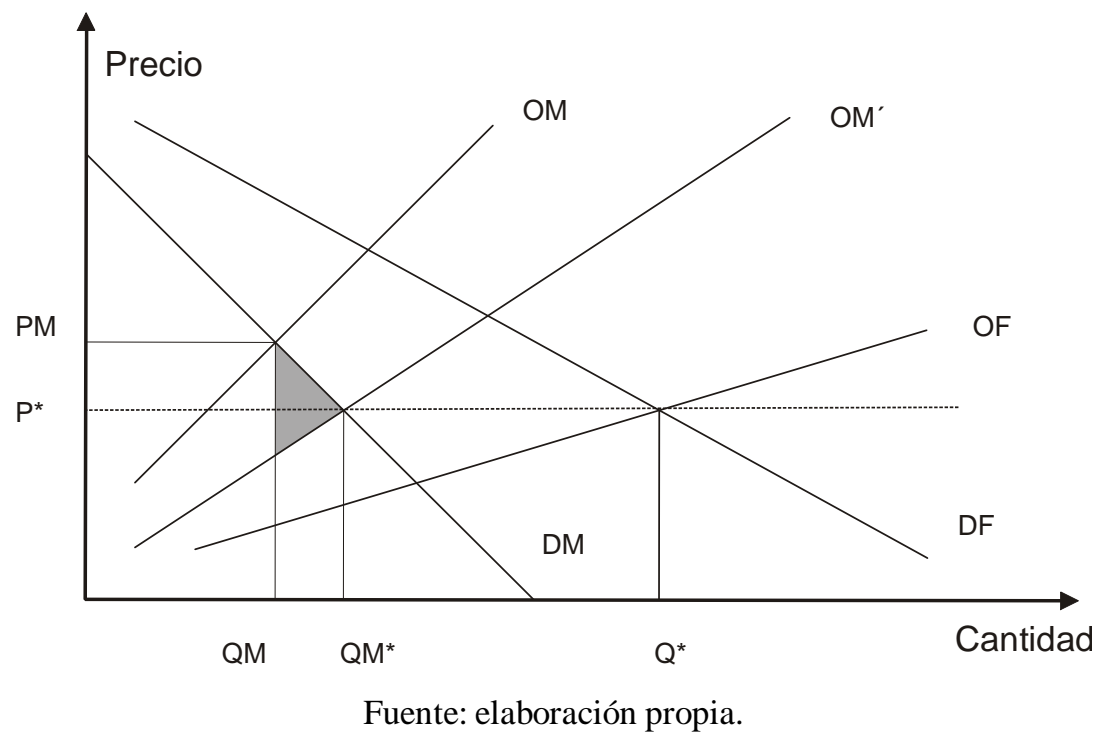

Sean las curvas OM y DM la oferta y la demanda de crédito en el segmento de población pobre, y sean OF y DF sus equivalentes en el sistema financiero formal. El equilibrio en el primer mercado ocurre a un nivel superior de tasa de interés y una cantidad baja de recursos transados. Por su parte, el mercado formal presenta la situación opuesta. Bajo el supuesto de que el mercado informal de capitales es solo una fracción mínima del sistema financiero, la integración de los mercados debería resultar en un equilibrio cercano a $\left(\mathrm{Q}^{*}, \mathrm{P}^{*}\right)$. La diferencia entre la disposición marginal a pagar DM en el segmento de población pobre, y el precio $\mathrm{P}^{*}$, incentivará el incremento de la oferta, mostrado en el gráfico en el desplazamiento de la curva de oferta de OM a OM'. Los oferentes se benefician, pues $\mathrm{P}^{*}$ es superior al costo marginal OM' entre las cantidades QM

$5 \quad$ La definición de IMF en distintos glosarios es muy genérica, incluye solamente la prestación de servicios microfinancieros y los objetivos de reducir la exclusión financiera e incrementar el bienestar de los destinatarios. 
y QM'; y los demandantes también se benefician, pues su disposición a pagar es superior a $\mathrm{P}^{*}$ en el mismo intervalo de la cantidad Q. La agregación de las dos formas de ganancia de bienestar queda representada por el área sombreada en el gráfico.

\subsection{Servicios adicionales al crédito}

Con relación al portafolio de servicios que algunas IMF, Organizaciones No Gubernamentales (ONG) u otros operadores añaden al suministro de crédito, existen posiciones contrapuestas. De una parte, muchas instituciones han mostrado su capacidad integradora de servicios unida a resultados financieros favorables, como es el caso de las instituciones CRECER en Bolivia y Share en la India. Pero en aquellos contextos donde la implementación de políticas de estímulo al pequeño emprendedor adquiere más despliegue que las iniciativas filantrópicas independientes, la opinión emitida apunta a que solamente las instituciones que se centren en el financiamiento lograrán ser exitosas a largo plazo. En algún sentido ambos planteamientos tienen margen de validez.

\subsection{Redefinición o ausencia de garantías}

Sobre este aspecto juega un papel clave la información asimétrica, dado que a causa de ella la institución prestamista no puede discernir, de la misma manera que en un entorno formal, quién es buen prestatario y quién no (Bebczuk, 2000).
Y la tasa de interés como único instrumento de control se muestra insuficiente y hasta contraproducente, ante la posibilidad de que se presenten situaciones de selección adversa, esto es, que solamente los candidatos de perfil más riesgoso sean efectivamente los que se conviertan en clientes.

Por tal motivo, las técnicas de selección de destinatarios de los créditos distan de ser triviales, y suponen un aprendizaje largo y dispendioso, el cual, por supuesto, eleva los costos operativos de la IMF. Con todo, la investigación emprendida sobre perfiles crediticios rinde su fruto, porque es posible a partir de ella delimitar el tipo de producto requerido y estructurar modelos de garantía de corte asociativo, solidario o mancomunado. Tales esquemas poseen la ventaja de que detrás del deudor hay un grupo social estructurado de apoyo, y adicionalmente, por cada unidad monetaria prestada, el valor de la garantía individual se reduce respecto de lo que regiría si no existiesen las citadas redes.

\section{Posicionamiento e interrelación con el resto del sistema financiero}

En general, todas las acciones de seguimiento hechas por autoridades o entidades prestatarias documentan avances notables de la actividad microcrediticia en los últimos años.

En 2006 alrededor de 967.000 microempresarios se hallaban registrados en Colombia ante las cámaras de 
comercio. La cifra es casi idéntica al cálculo del BID, por el cual se determinó que existían 965.435 clientes del microcrédito en el país (BID \& FOMIN, 2008). Pero estadísticas de las ONG señalaban que existían alrededor de 4.1 millones de microempresas unipersonales no registradas. Las microempresas equivalían al $97 \%$ de las empresas del país y ocupaban el $62.9 \%$ del empleo total (INCAE, 2007), y desde aquel entonces hasta la actualidad tales proporciones no son susceptibles de grandes cambios.

Según el programa de Banca de las Oportunidades, el índice de bancarización se ha incrementado de $47.06 \%$ en julio de 2006 a $55.60 \%$ en septiembre de 2008 (Bancoldex, 2009).

Las metas de política del programa en el Plan Nacional de Desarrollo 2006-2010 fueron las siguientes (Banca de las Oportunidades, 2009):

- Cobertura financiera a todos los municipios en el 2010.

- Total créditos a microempresarios: 5.000.000, distribuidos así: 2,000,000 entre Bancos y CFC, 2,750,000 por ONG y 250,000 por cooperativas.

- 850,000 nuevos asociados al sector cooperativo.

En lo que concierne a instituciones multilaterales, el BID-FOMIN ha brindado apoyos entre 2003 y 2006 a 35 instituciones de microcrédito, y ha hecho desembolsos a seis instituciones no reguladas (BID, 2007). Indirectamente también el estímulo al emprendedor, como política activa, contribuye a la mejoría en los indicadores del mercado laboral (Minprotección Social, 2006).

Diversas son las variables que pueden brindar una idea de cómo el microcrédito ha ido obteniendo tanto reconocimiento institucional como un espacio importante dentro del mercado de recursos de financiamiento. Las siguientes subsecciones muestran algunos de los indicadores más representativos que enlazan tales variables de actividad.

\subsection{Cartera}

El Gráfico 2 muestra la evolución de las carteras bruta y vencida, así como el indicador de calidad (vencida/bruta). En un lapso de solo tres años, de 2006 a 2009, la cartera del microcrédito se incrementó en más del $100 \%$, de \$1,67 billones a $\$ 3,80$ billones. Dado que en la segunda mitad del período mejoró de manera muy notable la calidad de la cartera, de $8,1 \%$ en marzo de 2008 a 5,7 $\%$ en diciembre de 2009 , se deduce que el crecimiento del total de obligaciones superó el crecimiento de las obligaciones vencidas. El deterioro de calidad previo pudo responder a la flexibilidad presentada en la otorgación de préstamos en razón al crecimiento económico en curso de esa coyuntura, lo cual motivó a las IMF a incurrir en mayores riesgos, parte de los cuales se materializaron. 
Logros, retos y oportunidades para el mercado del microfinanciamiento ... Hugo A. Hernández E. - J hon A. M éndez S. - N ubia S. Carreño A.

Gráfico 2. Cartera de microcrédito - Establecimientos de crédito (dic. 2006 - dic. 2009) Miles de millones de pesos de 2009

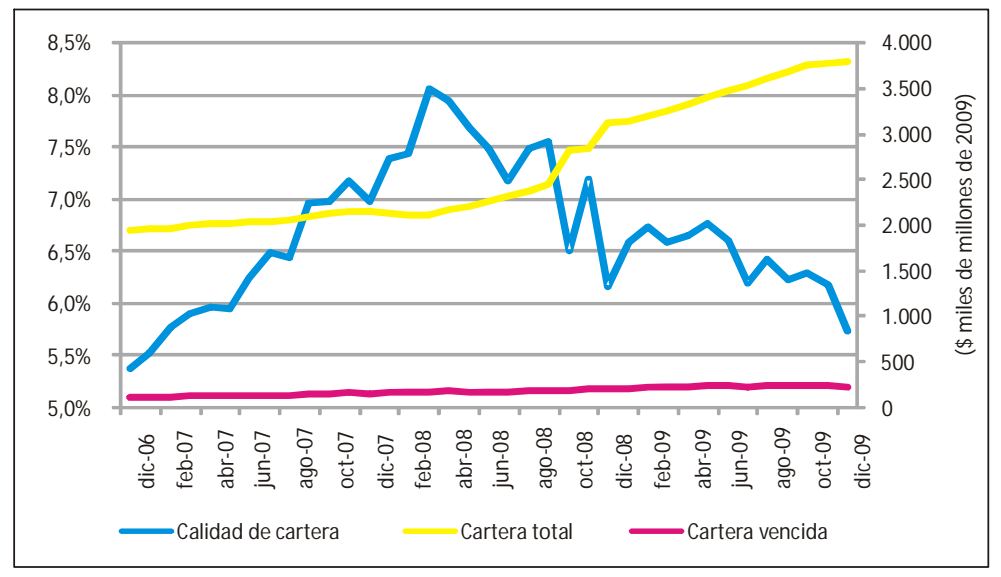

Fuente: Superintendencia Financiera de Colombia, página web. Nota: la calidad de cartera se representa en el eje vertical izquierdo; la cartera total y la cartera vencida se representan en el eje vertical derecho.

Tabla 1. Distribución por entidades de la cartera de microcrédito (marzo de 2010)

\begin{tabular}{|l|r|}
\hline \multicolumn{1}{|c|}{ Entidad } & \multicolumn{1}{|c|}{$\begin{array}{c}\text { Cartera bruta } \\
\text { (\$ millones) }\end{array}$} \\
\hline Banco Agrario & 1.978 .468 \\
BCSC & 600.146 \\
Bancamía & 501.172 \\
WWB Colombia & 479.531 \\
FMM Popayán & 429.032 \\
FMM Bucaramanga & 267.278 \\
Banco de Bogotá & 207.387 \\
Bancolombia & 207.381 \\
Finamérica & 114.760 \\
Fin. Comultrasan & 61.968 \\
Crediservir & 51.636 \\
Interactuar & 51.335 \\
Otros & 449.906 (aprox.) \\
Total & 5.400 .000 (aprox.) \\
\hline
\end{tabular}

Fuente: Cooperativa Emprender. 
Por lo que concierne a la distribución de las obligaciones, la Tabla 1 destaca al Banco Agrario como la entidad con la mayor cantidad de microcrédito desembolsado, seguido por el Banco Caja Social Colmena, Bancamía y el WWB Colombia. Nótese también que al incorporar las entidades no vigiladas por Superfinanciera, el universo de recursos se expande hasta un total de cartera bruta de $\$ 5,4$ billones.

Al comparar el conjunto de establecimientos de crédito de la banca tradicional con las IMF objeto de menores regulaciones, es decir las instituciones que propenden por un "tratamiento no bancario" del cliente, la diferencia en el registro de calidad de cartera (Gráfico 3) salta a la vista. Mientras que las ONG y las cooperativas de ahorro y crédito se encuentran más de un punto porcentual por debajo del promedio del total de establecimientos $(5,53 \%)$, ocurre una situación muy distinta con las Compañías de Financiamiento Comercial (CFC), los bancos y las cooperativas financieras. En este último grupo el indicador es el más deficiente, $7,97 \%$, posiblemente como herencia del episodio de crisis financiera de fines de los años noventa.

Al tomar estos mismos grupos de entidades, se encuentra, no obstante, que hay una fuerte concentración de recursos en los bancos (Gráfico 4), y que las entidades con mejor calidad de colocaciones, las ONG, alcanzan una cuarta parte de la cartera. Los demás establecimientos tienen participaciones reducidas en el agregado del microcrédito.

Gráfico 3. Calidad de cartera por tipo de establecimiento (marzo de 2010)

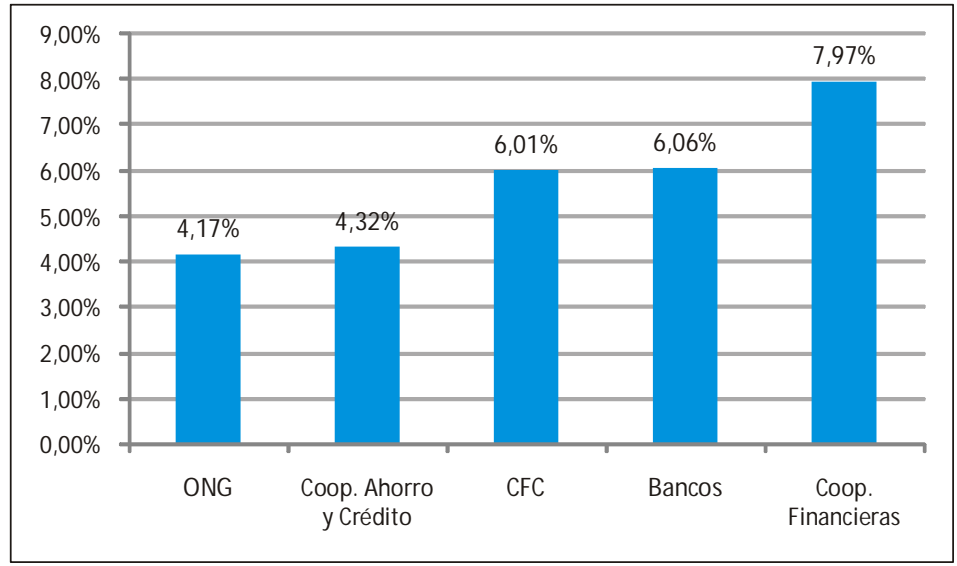

Fuente: Cooperativa Emprender. 
Logros, retos y oportunidades para el mercado del microfinanciamiento ... Hugo A. Hernández E. - J hon A. M éndez S. - N ubia S. Carreño A.

Gráfico 4. Cartera por tipo de operador (marzo de 2010)

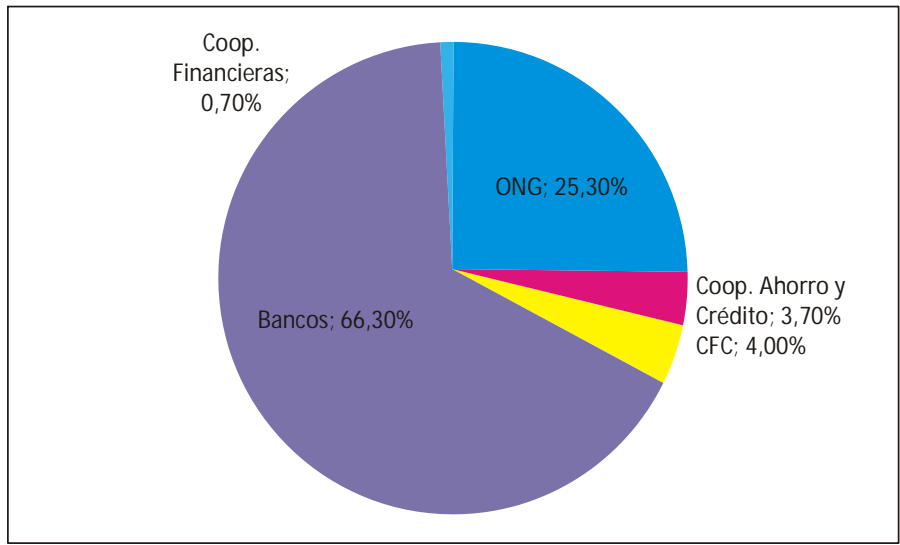

Fuente: Cooperativa Emprender.

Gráfico 5. Desembolsos de crédito - Total del sistema financiero y microcrédito (dic. 2006 - dic. 2009). Millones de pesos de 2009

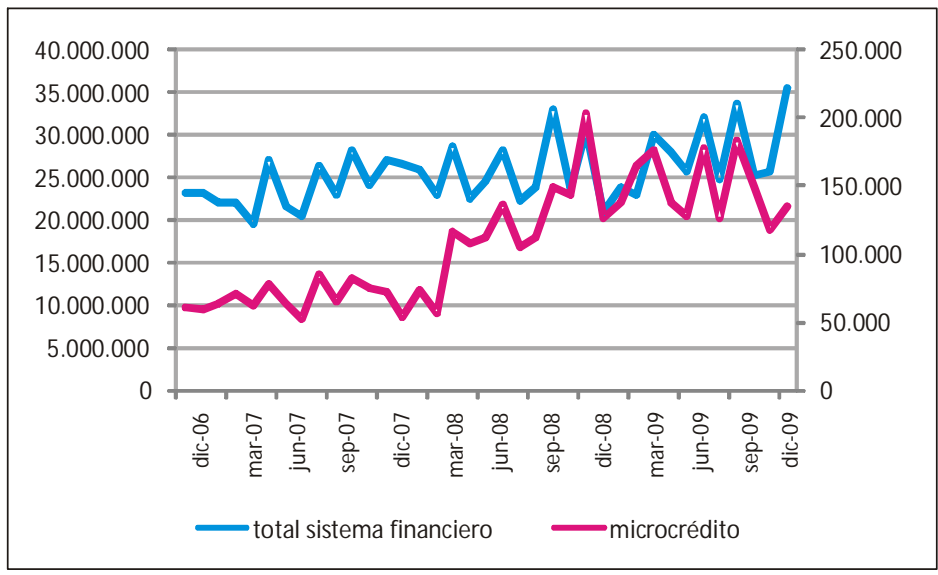

Fuente: Superintendencia Financiera de Colombia. Nota: los desembolsos del total del sistema financiero se representan en el eje vertical izquierdo; los desembolsos de microcrédito se representan en el eje vertical derecho.

\subsection{Desembolsos de recursos}

Si bien las cifras destacadas del microcrédito pueden dar la impresión de un eventual agotamiento del espacio potencial para otorgar financiamiento, ello se percibe como muy lejano en relación con las cifras agregadas del sistema financiero. 
Mientras que los fondos desembolsados totales del sistema mes a mes durante el período 2007-2009 han excedido casi sin excepción los $\$ 20$ billones, en el segmento del microcrédito los desembolsos mensuales solamente cruzaron el umbral de $\$ 80.000$ millones en abril de 2008 (Gráfico 5), pero a partir de entonces elevaron de modo muy importante su nivel, hasta bordear los 200.000 millones en algunos registros mensuales. Si tales saltos de escala siguen presentándose, quedará evidenciado que hay mucho espacio para el crecimiento del crédito a las unidades productivas más pequeñas, no solo porque existan políticas públicas para el efecto sino porque las condiciones de mercado invitan a bancos y demás IMF a seguirse acercando al segmento microempresarial.

Naturalmente, debe distinguirse entre el volumen de operaciones crediticias y el de usuarios beneficiados, ya que muchos microempresarios y emprendedores han sido receptores de múltiples desembolsos. Se calcula que entre 2002 y 2008 las nuevas vinculaciones al financiamiento formal cobijaron a 676.000 personas (Banco Caja Social Colmena, 2009).

Aparte de las cifras anteriores, es importante mencionar que desde un punto de vista cualitativo, el enfoque de las microfinanzas orientadas solo para el emprendimiento viene siendo superado. Así, por ejemplo, en Argentina se concibe la otorgación de microcréditos para consumo y para construcción y mejora de vivienda, lo cual redunda en la apropiación de bienes de capital, y por ende en la superación de desigualdades (Fundación Andares, s.f.).

La aplicación de programas de microcrédito no se encuentra exenta de dificultades de orden práctico. Así, por ejemplo, en Brasil y Chile se encontró que algunos beneficiarios no correspondían necesariamente a población pobre, pero esto no impidió que tales programas elevaran el ingreso de los beneficiarios (Rodríguez, s.f.). Y si bien algunos estudios empíricos han mostrado impactos favorables del microcrédito, se presume que estos análisis no han considerado períodos suficientes para detectar las verdaderas mejoras que puede proveer esta herramienta (Olaya, 2008).

Aunque las cifras del microcrédito disten de los volúmenes de recursos transados por el resto del sistema financiero, en términos de ganancias de bienestar, la presencia de esta herramienta ha significado mucho para sus beneficiarios. Así por ejemplo, para algunos receptores de microcrédito, el acceso a esta oportunidad ha posibilitado cosas tan simples e importantes a la vez como tener tres comidas al día (Daley-Harris, 2009). Ello da una idea de la trascendencia que tiene acometer evaluaciones de impactos puntuales.

\section{Evolución del marco institucional de las microfinanzas}

Una vez estructurada una IMF y alcanzada su viabilidad económica, el 
siguiente paso en su evolución ha sido la diversificación de productos. Si bien el centro de la actividad microfinanciera sigue siendo el crédito, muchas instituciones han ampliado su portafolio de productos con especial énfasis en el ahorro, ya no como una actividad accesoria de la IMF sino como base de fondeo para los préstamos. De allí que el concepto de microcrédito antecediera al de microfinanzas. Para tales efectos, entidades como el Banco Procredit vienen avanzando mediante requisitos muy accesibles para la apertura de cuentas (informativo Ecosolidario, 2008). También está alcanzando una evolución muy favorable la industria de los microseguros: de vida, salud, bienes materiales y discapacidad (Rivera, 2009).

Luego de la diversificación están dadas las condiciones para que entre a operar la regulación financiera, especialmente enfocada a la calidad de los servicios y a la paulatina reducción de sus costos, en un ambiente de promoción de la competencia. Por ejemplo, en Bolivia la tasa efectiva descendió de $6 \%$ mensual a comienzos de los noventa a cerca de $2 \%$ en la actualidad. También la cobertura se ha visto favorecida enormemente en aquella nación, hasta el punto de que se estima que cerca del $50 \%$ de todos los microempresarios del país ha accedido a algún servicio microfinanciero.

Aunque muchas entidades pioneras en actividades de microfinanzas fueron ONG, se encontró que tal condición dificultaba la evolución hacia un reconocimiento pleno del entorno económico formal, por lo que paralelamente con el proceso de evolución de los servicios financieros, tales instituciones también fueron objeto de transformación, de modo que fueran alcanzando el citado reconocimiento, o bien bajo el rótulo de IMF o integrándose plenamente con la banca tradicional. La corporación Acción Internacional distingue tres modelos básicos de entidades microfinancieras:

- Bancos comerciales especializados en microfinanzas

- Compañías subsidiarias de un banco especialmente dedicadas a las microfinanzas

- Bancos estatales con servicios ajustados a las necesidades de los microempresarios

La recomposición del sector microfinanciero parece haberse estabilizado en los últimos años en América Latina. Cerca del $50 \%$ de los usuarios son atendidos por ONG, $25 \%$ por entidades reguladas no bancarias, como las compañías de financiamiento comercial, $y$ el restante $25 \%$ bancos (Gaceta Financiera, 2009). Mientras que en Colombia hace dos décadas el sector de las microfinanzas se componía básicamente de ONG, en la actualidad el protagonismo procede de instituciones financieras reguladas (Aristizábal, 2007).

Como fue expresado previamente, la experiencia ha mostrado también que los 
productos o servicios no financieros, manejados originalmente por las ONG para complementar el apoyo a los solicitantes de crédito, como la capacitación, asesoría o formas diversas de acompañamiento, han ido perdiendo protagonismo en la medida que generaban costos muy ostensibles para la entidad microfinanciera y bloqueaban su especialización a futuro. Ahora estas dos esferas, la del financiamiento y la de servicios complementarios, cada vez se separan más, permitiéndole a muchas IMF centrarse estrictamente en la gestión del circuito entre crédito y ahorro. Por supuesto, ello facilita también la gestión de las ONG cuya vocación es el apoyo al empresarismo.

Cada producto o servicio puede tener un tipo de actor institucional especializado. En el caso colombiano, las cajas de compensación familiar serían las llamadas a profundizar en el segmento referido al mejoramiento de vivienda (Gnecco, 2009). Las cajas han concentrado tradicionalmente su actividad nuclear alrededor de la gestión de subsidios de vivienda, mercadeo, salud y capacitación, pero el crédito a emprendedores ha ido ganando terreno dentro de su portafolio, aunque a ritmo lento respecto de otras instituciones. Entre 2003 y 2009 (enero) las cajas entregaron 4.982 microcréditos de un total de 5.184 solicitudes recibidas, es decir una porción todavía reducida respecto del universo de usuarios (Minprotección Social, 2009).

También es de recalcar que no han sido prósperos los experimentos que reúnen en una misma institución el crédito a la microempresa con el crédito de consumo a grupos poblacionales vulnerables, dado que ello ha significado pérdidas, deterioro institucional y reforzamiento de la condición de pobreza en los clientes. Como el aprendizaje de la técnica de gestión microcrediticia es dispendioso, es fundamental el apoyo de entidades con mayor trayectoria a través de estructuras en red o el acompañamiento de ONG promotoras con mucha experiencia.

En lo que concierne a la transformación en el perfil de una entidad, la Economist Intelligence Unit $^{6}$ ha detectado que en Colombia existen dificultades para la ampliación de la cobertura regulatoria sobre las IMF, debido entre otras razones a que para que las ONG evolucionen y se conviertan en sociedades financieras o bancos deben adecuarse a los mismos requisitos de constitución de tales instituciones (Economist Intelligence Unit, 2009). Aunque las acciones de regulación operan en múltiples dimensiones, tradicionalmente el criterio que separa lo regulado de lo no regulado es la captación de recursos del público, y por ende para alcanzar el estatus de

\footnotetext{
$6 \quad$ La Economist Intelligence Unit es una firma de investigación económica con más de 40 oficinas en distintas partes del mundo. Fue fundada en 1946, y ofrece información sobre economías nacionales relativa a más de 200 tipos de mercados. Página web: www.eiu.com
} 
regulable una entidad microfinanciera debería aspirar a contar con una sección de ahorro (Zea, 2007).

Ante la ausencia de paradigmas en materia de microfinanciamiento, debe decirse que el hecho de que determinada estrategia microcrediticia haya tenido éxito en otras partes, no significa que sea universalmente aplicable. Los modelos de asistencialismo presentan el riesgo de que los donantes de recursos en algún momento opten por otras alternativas de inversión en capital social, como educación o salud (Suárez, 2007).

En consecuencia, es deseable que las herramientas microfinancieras apunten en el futuro a un verdadero empoderamiento, no concebido exclusivamente en el marco restringido de los proyectos productivos, sino llevado a un nivel estratégico, de toma de posiciones de liderazgo en el mercado por parte de los emprendedores (Pait, 2009).

\section{Conclusiones}

Si bien a nivel teórico es manifiestamente comprensible que existe el "espacio económico" para surtir de financiamiento a grupos de población tradicionalmente excluidos de la banca tradicional, la simple argumentación de que su nivel de bienestar puede aumentar sustancialmente no basta por sí sola para garantizar el éxito de una iniciativa microcrediticia. El mejor aprovechamiento del crédito trae implícita la tesis de que el pequeño emprendedor es al menos tan productivo como su contraparte en los estratos atendidos por la banca.

Como tal, no se dispone de una taxonomía que facilite la identificación de cuál deberá ser el modelo exitoso de las microfinanzas. De la mecánica de ensayo-error han surgido rasgos idiosincráticos que en cada país ayudan a comprender el curso del sector de las IMF (Larraín, 2009). De hecho, parte de la práctica de las IMF con más tradición es precisamente superar la barrera informativa mediante un cuidadoso seguimiento y atención personalizada que el sistema financiero formal no ofrece. Ello, aunque signifique costos adicionales, consigué en parte resolver el problema tanto de la selección como de la garantía, lográndose niveles de cartera vencida muy bajos. De tal modo se puede de manera muy básica validar el postulado de Yunus sobre la calidad en el cumplimiento de las obligaciones por parte de los pequeños emprendedores, lo cual les amerita secuencialmente acceder a montos más grandes de crédito para hacer crecer sus unidades productivas.

La comparación estadística con el agregado del sistema financiero colombiano muestra que el espacio crediticio por conquistar es amplísimo, pero ello no tiene que traducirse en una estrategia de bancarización acelerada y riesgosa, puesto que tal tendencia ha conllevado en el pasado a mayores niveles de morosidad. Este planteamiento es consecuente con el registro de calidad de cartera, el cual favorece a las ONG y las 
cooperativas de ahorro y crédito, entidades más afines al concepto de IMF tradicional que al de financiamiento bancario. Por ende, el criterio de los menores costos del crédito no tiene necesariamente que recibir prerrogativas frente a la canasta adicional de servicios de asistencia y acompañamiento provisto por las IMF no bancarias.

\section{R eferencias bibliográficas}

1. Aristizábal, R. (2007). El microcrédito como alternativa de crecimiento en la economía colombiana. Recuperado el 16 de mayo de 2010, de <http:// www.portalmicrofinanzas.org/g m/ document-1.9.37392Microcr\%C3\%A9 dito\%20Colombia\%202007.pdf>.

2. Asobancaria. (29 de marzo, 2010). Informe semanal de regulación. Recuperado el 22 de mayo de 2010, de <http:// www.asobancaria.com/upload/docs/ docPub5298_1.pdf>.

3. Avendaño, H. (2006). ¿Es demasiado costoso el microcrédito en Colombia? Recuperado el 12 de mayo de 2010, de <http://www.mincomercio.gov.co/ eContent/documentos/publicaciones/ EscostosoelmicrocreditoenColombia.pdf>.

4. Banca de las Oportunidades. (2009). Informe Programa de Inversión Banca de las Oportunidades (PIBO) EneroSeptiembre de 2009. Recuperado el 15 de mayo de 2010, de <http://www.bancadelas oportunidades.com.co/documentos/ Logros\% 20-\%20Informeinforme septiembre_\%202009.pdf>

5. Banco Agrario de Colombia. (2007). El sistema de financiamiento para el agro. Recuperado el 10 de mayo de 2010, de <http://www.bancosdesarrollo.org/ facipub/upload/publicaciones/1/85/ banagrario-colombia.pdf $>$.

6. Banco de la República. (Septiembre, 2009). Ampliación del acceso a los servicios financieros. Recuperado el 20 de mayo de 2010, de <http://www.banrep.gov.co/ d ocumentos / publicaciones / revista_bco_notas/2009/septiembre.pdf>.

7. Banco de la República. (Marzo, 2010). Reporte de la situación del crédito en Colombia Recuperado el 2 de mayo de 2010, de <http://www.banrep.gov.co/ documentos/informes-economicos/ encuestas/SCC/2010/credito_marzo .pdf>.

8. Banco Interamericano de Desarrollo BID. (2007). Estrategia del Banco con Colombia 2007-2010. Recuperado el 6 de mayo de 2010, de <http://www.accion social.gov.co/documentos/Cooperacion\% 20Internacional/VII-Encuentro-SNCI/ Estrategias\%20Pais/Estrategia\%20PaisEspanol\%20BID.pdf>.

9. Banco Interamericano de Desarrollo, Fondo Multilateral de Inversiones FOMIN. (2008). Microfinanzas en América Latina y el Caribe: Datos 2008. Recuperado el 5 de mayo de 2010, de <http:// 
www.microfinanzas.org/uploads/media/ 1673931-Resumendatosdemicrofinanzas 2008.pdf>.

10. Bancoldex. (29 de mayo, 2009,). Microcrédito en Colombia.Aumenta índice de bancarización Recuperado el 30 de mayo de 2010, de <http://www. bancoldex.com/documentos/1497 146_BBX_Pibo_cifras.pdf>.

11. BCSC. (Mayo, 2009). Inclusión financiera. Caso del banco BCSC Colombia. Recuperado el 3 de mayo de 2010, de <http://www.wsbi.org/uploadedFiles/ Events/Eulalia\%20Arboleda.pdf $>$.

12. Bebczuk, R. (2000). Información asimétrica en los mercados financieros. Madrid: Cambridge University Press.

13. Confederación de Cooperativas de Colombia. (2006). Sector cooperativo financiero a diciembre de 2005. Recuperado el 3 de mayo de 2010, de <http://www.aciamericas.coop/IMG/ colombia_financiero2005.pdf>.

14. Congreso de la República. (10 de julio, 2000). Ley 590 de 2000. Recuperado el 28 de mayo de 2010, de <http://www.sena. edu.co/nr/rdonlyres/2689d187-3ca8-4d1ab 2 d d - 1312 d f 801 e b $2 / 0$ / ley590de2000mipymes.pdf>.

15. Consumidores Colombia COCO. (Junio, 2009). Crédito y sobreendeudamiento de los Consumidores. Recuperado el 23 de mayo de 2010, de <http://www.consumi doresandinos.com/documentos/campanas /4/estudios/sobreendeudamiento colombia.pdf $>$.

16. Cooperativa Emprender. (14 de abril, 2008). Boletín Microfinanciero.
Recuperado el 2 de mayo de 2010, de <http://www.cooperativaemprender.com/ uploads/media/Comentarios_al_ Decreto_919_de_2008_14.pdf>..

17. Córdova, D. (2010). Derrota de la pobreza, emprendedores y microfinanzas. Perspectiva, (23). Recuperado el 26 de mayo de 2010, de <http://perspectiva .icpcolombia.org/archivos/revista/ No\%2023/050-054\%20PERS\%20 OK.pdf $>$.

18. Corporación Andina de Fomento CAF, Dirección de Pyme y Microfinanzas. (Mayo, 2005). CAF y microfinanzas: una alianza en crecimiento. Recuperado el 18 de mayo de 2010, de <http://www.caf.com /attach/17/default/cafymicrofinan zas.pdf>.

19. Cuéllar, M. M. (2009). Avances y los obstáculos de la bancarización en Colombia. Recuperado el 29 de octubre de 2010, de <https://www.bmi.gob.sv/pls/ portal/docs/page/bmi_htmls/ bmi_pulso_mype_img/bancarizacion _colombia.pdf>.

20. Daley-Harris, S. (2009). Informe del estado de la campaña de la Cumbre de Microcrédito 2009. Recuperado el 24 de mayo de 2010, de <http://www.microcre ditsummit.org/uploads/socrs/SOCR 2009_Spanish.pdf>.

21. Economist Intelligence Unit. (2009). Microscopio global sobre el entorno de negocios para las microfinanzas. Recuperado el 8 de mayo de 2010, de <http://www.caf.com/attach/17/default/ GlobalMicroscope_SP_WEB_Sept25.pdf>.

22. Ecosolidario. (2008). Avanzada del microcrédito en Colombia. Recuperado el 
4 de mayo de 2010, de <http:// www.procredit.com.hn/uploaded/content/ category/934493199.pdf>.

23. Fajury, L. (Marzo, 2009). Rol del estado en el fomento de las microfinanzas: el caso colombiano. Recuperado el 3 de mayo de 2010, de <http://ppuc.lemongroup.cl/ media/proyectos/material/352_ Presentacion_de_Lizbeth_Fajury:_caso_ colombiano.pdf $>$.

24. Fardelli, C. (2006). Características de la gestión de ONG's de microcrédito. Estudio de casos. Recuperado el 15 de mayo de 2010, de <http://www.portal $\mathrm{microfinanzas.org} / \mathrm{g} \mathrm{m} / \mathrm{document}$ 1.9.36256/Caracteristicas $\% 20 \mathrm{de} \%$ 20la\%20gestion\%20.pdf>.

25. Ferrari, C. (Abril, 2004). Desarrollo y microcréditos: el Grameen Bank y su replicación. En Hacia el 2005, año internacional del Microcrédito. Ponencia para el Primer Simposio Internacional de Microcréditos, llevado a cabo en la Pontificia Universidad Javeriana, Facultad de Ciencias Económicas y Administrativas, Cali.

26. Financiera Compartir. (2010, marzo). Informe de responsabilidad social 2009. Recuperado el 9 de mayo de 2010, de <http://www.financieracompartir.com/ e Content/library/documents / DocNewsNo87DocumentNo81.PDF>.

27. Fundación Andares. (s.f.). Estudio progresivo para construcción de vivienda. Recuperado el 2 de mayo de 2010, de <http://www.fundacionandares.org/ files_upload/Castelli.pdf>.

28. Gaceta Financiera. (2009). ¿Qué es el microcrédito? Recuperado el 28 de mayo de 2010, de <http://www.gacetafinanciera .com/MCr.pdf $>$.

29. Giraldo, S. (2009). Análisis de los alcances y limitaciones de los programas de microcrédito. Recuperado el 14 de mayo de 2010, de <http://repository.urosario. edu.co/bitstream/10336/1288/1/ 1032412344.pdf>.

30. Gnecco, F. (Mayo, 2009). Cajas de compensación familiar. En Seminario crédito y microcrédito. Llevado a cabo en Barranquilla. Recuperado el 23 de mayo de 2010, de <http://www.ssf.gov.co/wps/ $\mathrm{wcm} /$ connect/7194d1804fa61655a36 dfbd5b423dbc5/Seminario $+\mathrm{Cr} \% \mathrm{C}$ $3 \%$ A9dito+Social+y+Microcr $\% \mathrm{C} 3 \%$ A9dito,+2009.pdf>.?MOD=AJPERES

31. INCAE. (2007). Bancolombia: el programa de ejecutivos de microcrédito. Recuperado el 3 de mayo de 2010, de <http://www.incae.com/ES/clacds/ nuestros-proyectos/archivo-proyectos/ proyectos-de-competitividad-clima-denegocios/programa-de-microfinanzas-delclacds-en-incae-business-school/pdf $>$.s/ Cas o- B a n c o lo mbi a_ 2 f e b 07 _FINAL.pdf>.

32. Larraín, C. (2009). ¿Existe un modelo de microfinanzas en América Latina? Recuperado el 27 de mayo de 2010, de <http://www.eclac.cl/publicaciones/xml/4/ 38264/lcl3147pe.pdf>.

33. Meléndez, D. (2007). Desarrollo efectivo de las microfinanzas en Colombia. Recuperado el 18 de mayo de 2010, de <http://www.idlo.int/MF/Documents/ Publications/38E.pdf $>$.

34. Ministerio de Comercio, Industria y Turismo. (2003). Política estatal de apoyo 
a las Mipymes. Recuperado el 7 de mayo de 2010, de <http:/www.mincomercio.gov. co/econtent/documentos/intervenciones/ 2003/ViceZ/apoyomipymes.pdf>.

35. Ministerio de Hacienda y Crédito Público. (2006). Decreto número 3078 de 2006. Recuperado el 4 de mayo de 2010, de $<$ http://www.bancadelasoportunidades. gov.co/documentos/dec_3078_programa _de_inversion_banca_oportunidades.pdf $>$.

36. Ministerio de la Protección Social. (2006). Lineamientos de la política de empleo 2006-2010. Recuperado el 16 de mayo de 2010, de <http://akane.udenar.edu.co/ omtp/dir2/memorias/MPS_Politica _empleo_2006-2010.pdf>.

37. Ministerio de la Protección Social. (Marzo, 2009). Principales indicadores laborales. Recuperado el 15 de mayo de 2010, de <http://www.minproteccionsocial.gov.co/ obtrabajo/pdf>./Boletines\%202009/ 1BOLETIN2009.pdf $>$.

38. Olaya, D. (2008). ¿De qué manera ayuda el microcrédito a disminuir la pobreza? Recuperado el 24 de mayo de 2010, de <http://www.seminariopublica.info/ maindata/seminario/200848-182747/ imagesdirs/PD32_OlayaMontoyaD.pdf>.

39. Otero, M. (Marzo, 2003). Tecnologías de microcrédito e instituciones microfinan cieras. En Prácticas Mundiales Exitosas en Microfinanzas. Simposiollevado a cabo en Cartagena.

40. Pait, S. (2009). Definiciones de empoderamiento y sistemas de información de género en las microfinanzas. La teoría y la práctica. Recuperado el 23 de mayo de 2010, de <http://www.sipromicro.org/ fileadminpdf $>$.s_biblioteca_SIPROMICRO/ 001525.pdf>
41. Rivera, J. \& Caro, J. (2009). Las microfinanzas y los microseguros en América Latina y el Caribe: situación y perspectivas. Recuperado el 29 de mayo de 2010, de <http://www.microseguros. info/uploads/media/Las_microfinanzas_ y_los_microseguros_en_America_LAtina _y_el_Caribe__Situacion_y_perpectivas. pdf>.

42. Rodríguez, C. (s.f.). Impacto de las microfinanzas: resultados de algunos estudios. Énfasis en el sector financiero. Recuperado el 8 de mayo de 2010, de <http://www.culturaemedellin.gov.co/ s i te s / CulturaE/Document s / Blog_JCE_071221_impactomicrofinanzas.pdf>.

43. Schneider, F. \& Ense, D. (2002). Ocultándose en las sombras. El crecimiento de la economía subterránea. Recuperado el 26 de octubre de 2010, de <http://www.imf.org/external/pubs/ft/ issues/issues30/esl/issue30s.pdf $>$.

44. Suárez, D. M. (2007). Microcrédito: herramienta contra las barreras de financiación. Recuperado el 20 de mayo de 2010, de <http://xue.unalmed.edu.co/ s eminariopublica/ponencias / Ponencia_29_suarezboterodm.pdf>.

45. Superintendencia Financiera de Colombia. (2 de abril, 1993). Decreto 663 de 1993, por el cual se actualiza el Estatuto Orgánico del Sistema Financiero y se modifica su titulación y numeración. Recuperado el 24 de mayo de 2010, de <http://www.superfinanciera.gov.co/ Normativa/normas.htm

46. Superintendencia Financiera de Colombia (26 de octubre, 2001,). Circular externa No. 50 de 2001: modificaciones a la circular básica contable y financiera. 
Recuperado el 18 de mayo de 2010, de <http://webview.javerianacali.edu.co/cgiolib/?infile=details.glu \&loid=343578\&rs $=190121$ \&hitno=-1

47. Superintendencia Financiera de Colombia. (5 de marzo, 2002). Circular externa No. 11 de 2002. Recuperado el 17 de mayo de 2010, de <http://www.fasecolda.com/ fasecolda/BancoMedios/Documentos $\% 20 \mathrm{PDF}>$./ce $\% 2011 \% 20 \mathrm{de} \% 2020$ 02.pdf $>$.

48. Superintendencia Financiera de Colombia (30 de marzo, 2007a). Resolución número 0428 de 2007. Recuperado el 28 de mayo de 2010, de <http://www.cijuf.org.co/ documentos/b21.pdf $>$.

49. Superintendencia Financiera de Colombia. (26 de febrero, 2007b). Microcrédito, certificaciones, interés bancario corriente. Recuperado el 19 de mayo de 2010, de $<$ ht t : / / w w w. superfinanciera. gov.co/Normativa/Conceptos $2007 /$ 2007000587.pdf>.

50. Superintendencia Financiera de Colombia. (14 de mayo, 2008). Microcrédito, disponible definición, cobro de honorarios $y$ comisiones. Recuperado el 29 de mayo de 2010, de <http://www.superfinanciera. gov.co/Normativa/Conceptos $2008 /$ 2008020150.pdf>.

51. Tafur, C. (2008). Bancarización: una aproximación al caso colombiano a la luz de América Latina. Recuperado el 3 de mayo de 2010, de <http://dspace.icesi. edu.co/dspace/bitstream/item/1918/1/ 1Claudia_Tafur_Bancarizacion.pdf $>$.

52. Universidad Sergio Arboleda, Escuela de Negocios y Ciencias Empresariales (Marzo, 2006). Las microfinanzas: un paso al desarrollo. Desempeño, obstáculos y necesidades de las instituciones micro financieras en Colombia. Recuperado el 23 de mayo de 2010, de <http:// w w w. u s e r g i o a r b o l e d a . edu.co/negocios/Microfina.pdf>.

53. Yunus, M. (1998). Hacia un mundo sin pobreza. Santiago de Chile: Andrés Bello.

54. Zea, C. (2007). Las microfinanzas y el supervisor financiero. Recuperado el 3 de mayo de 2010, de <http://www.swwb.org/ files/11_Camilo_Zea_Gomez_Super intedente_Colombia.pdf $>$. 